\title{
Prime Minister Painter Han Huang and His Rural Life Works
}

\author{
Chunsheng Xing \\ Arts and Design School \\ Huanghe Science and Technology College \\ Zhengzhou, Henan, 450005 \\ e-mail:11781899@qq.com
}

\begin{abstract}
Han Huang was the prime minister during the reign of Emperor Daizong in Tang Dynasty (726-779). Compared with his rough official experiences, his achievements in painting have always been recognized by the public. Han Huang often went to the countryside to investigate mass condition and incorporated his attention to agriculture and his sympathy for farmers into his painting works during his long-term administration of local works, thus he created lots of masterpieces of rural life.
\end{abstract}

Keywords-Han Huang; painting; rural life

\section{INTRODUCTION}

Tang Dynasty (618-907) was a period of talents in ancient China and there was no lack of famous historical writers, calligraphers or painters among the officials of prime minister. For example, Yu Shinan, Yan Zhenqing and many other great calligraphers all once held the post of prime minister in Tang Dynasty, and after Yan Zhenqing, another prime minister well-known for his painting works appeared in the reign of Emperor Daizong, namely, Han Huang. Han Huang was an honest and upright official with capacity of state governance and military management. However, due to his multiple personality and shortcomings in his official business, more records were made for his achievements in painting by later generations. One of his representative works Five Cows Figure was praised as "a rare piece", [1]54-56 is a classic work in Chinese painting history and now kept in the Palace Museum to tell the public a historical story about Han Huang's painting as a national art treasure.

\section{Rough OFFICIAL CAREER AND GOOD REPUTATION}

In 723 A.D, Han Huang was born in an aristocratic family in Chang'an, the capital of Tang Dynasty. His father Han Lin once served as the arts teacher of the crown prince. In his childhood, Han Huang was bright, upright and studious. In his adulthood, he directly reached a higher level due to his superior family status and served as a military staff. At the beginning of his official career, he originally intended to make all-out efforts to share the worries of the nation and be faithful to the emperor, however, sinister officialdom made his official career rough from the very beginning. The cause of the matter was that Han Huang's elder brother Han Fa was upright and once offended Wang $\mathrm{Yu}$ who also held office at court, later Wang $\mathrm{Yu}$ had a meteoric rise and became the prime minister assuming power in hand and intending to retaliate against Han $\mathrm{Fa}$ with his power. Wang $\mathrm{Yu}$ ordered that the Hans should not be promoted and could only hold their original post or be relegated to relatively idle government office. Han Huang was also involved and forced to put down the original grand political ambitions and "laze away". Till Wang Yu was removed from his post, civil and military officials told the emperor the unfair treatment the Hans had suffered. So Han Huang was rapidly promoted to be a Yuanwai Lang in the Ministry of Official Personnel Affairs. With intentional cultivation of the state, Han Huang was sent to local government to receive training.

During his tenure in Suzhou, Han Huang was very sympathy for the farmers who worked hard and then had enough to eat and wear; he took the pain of the farmers as his own pain and made many efforts to help agricultural development and improvement of farmers' life. To restore order in agricultural production and countryside vitality that were once damaged by An-Shi Disturbances, Han Huang took the vast majority of his salary and government taxes to reward agricultural reward. To clean up the surtaxes and make farmers restorative and regenerative, Han Huang first went to the farm land to investigate specific conditions and then released government documents to remove unreasonable surtaxes one by one. He also actively assisted the farmers in fertilizer procurement, transportation, use and other matters, went to the farm land with the farmers to regulate rivers and watercourses and breed fish and arranged farmland water conservancy establishment in order to ensure stable yields despite drought or excessive rain. Such efforts made by Han Huang not only had promoted agricultural recovery in Suzhou region, but also won him the respect and support from the public. While paying attention to agricultural development, Han Huang also very carefully found that oxen and horses were indispensable in agricultural production. So he ordered a ban on export of oxen and horses and slaughter of cattle in the area under his jurisdiction. Several years later, rural areas under his jurisdiction had good harvests in succession and his achievements were also spread around. [2]138-140 


\section{EXPERIENCE OF SUFFERING OF THE PUBLIC AND EMOTIONAL EXPRESSION IN PAINTING}

During his tenure, Han Huang spent most of his time in understanding and solving hardships of the public and his understanding and love for rural life broadened his horizon and enriched his inner feeling. Han Huang who inherited the literary temperament of his family started to describe rural life and express his own feeling in the form of paintings in his spare time. A celebrity named Zhu Jingxuan in Tang Dynasty gave extremely high praise to Han Huang's works of rural life, saying "buffaloes, farmers and other rural customs all show themselves creatively in Han Huang's works." For example, Rural Customs Figure was painted by Han Huang when he saw hardworking farmers work in the field whole day and make a precarious living. Rural Customs Figure described the tough farming lifestyle of the farmers and could be divided into farm irrigation, reaping and harvests, ears of wheat and rice screening and grinding, etc., and each part was accompanied with a poem, vividly reflecting the whole process of agricultural production made by the farmers in the form of painting and calligraphy and indicating that Han Huang was very familiar with agricultural production, rather than a mediocre officer not knowing farming. A poem attached to the painting was just a touch that brought the painting to life. In the image of warehousing, Han Huang inscribed a poem, saying "the farmers worry about taxes though they have harvests." It means that the farmers began to worry about their heavy taxes before they had enough time to celebrate their harvest and full barns. Perfect combination of poem and painting not only expressed painting skills of Han Huang, but also reflected his style of realism. Han Huang's achievements in painting were recognized by the later generation just because the close combination of his style of realism and seriousness about painting. Han Huang also once said "Before painting, I will always first confirm the prototype of the creation material in daily life and think about. I will not begin to paint if I have no well-thought-out plan."

Painting was a plaything of upper class in ancient China or only circulated among litterateurs. Subject matter of painting might be magnificent landscape or indoors royal figures and their activities, or interesting flowers and birds and rare works and painters took low-class labors, rural life and agricultural production as their subject matter. However, Han Huang was not only the first one to create works of rural life among ancient painters, but also the one with the largest amount of works of this subject. Nearly 40 pieces of works of Han Huang were collected in Xuanhe Painting Works, including rural customs-themed Hunting In Snowy Weather, Rural Children Playing with Ants, Harvest Figure, Village Community, Relocation of Farm House and Rural Customs Figures, etc., rural people-themed Soil Block Hitting Play by People in Emperor Yao Period, Group of Seven and Li Deyu Entertaining Guests, rural livestock-themed Diary Cow, Old Bank Cow, Home Coming after Livestock Grazing and Community Bullfight, etc. When well-known civil officer Lu You in Song Dynasty (960-1279) saw a few authentic works of Han Huang by accident, he can't help sighing with emotion "When I see a farmer grazing cows in grasses and trees in the figure, I am personally on the scene and the aspiration becomes much stronger for me to retire from official life." [3]163-164 Han Huang's Soil Block Hitting Play by People in Emperor Yao Period was just one of the works highly appreciated by Lu You, fully reflecting Han Huang's paying for warm weather and good harvest for the country. Different from Han Huang's other works of rural life, Soil Block Hitting Play by People in Emperor Yao Period was not realistic, instead, it was created based on a legend. According to the legend, during the reign of Emperor Yao, people had sufficient food and lived in a harmonious society, a man hit soil blocks in the field, so people called him Soil Father and believed he had "the virtue of emperor". But Soil Father said "I get up at sunrise and rest at sunset and I just live on the field, I have no virtue and power of emperor." Han Huang drew this figure according to the legend just for showing simple character of laboring people.

Han Huang liked cows very much and he regarded cows as an indispensable beneficial animal to agricultural production and rural life. His love for cows created his inner for cows and further made him passionate about creation that is to describe cows in his works. Han Huang was therefore called as the most famous cow-themed painter in the painting history in ancient China. Famous painting critic in Tang Dynasty named Zhang Yanyuan once said that "Han Huang works best in cow and sheep figures." Through years of careful observation on cows, Han Huang made analysis, survey and selection carefully and created the beautiful Five Cows Figure.

\section{VIVID IMAgE OF FIVE COWS, wITH UNIQUE SKILlS}

Five Cows Figure, just as its name implies, five cows in the figure are its subject. In Han Huang's figure, these five cows have different expressions, some of them are bowing and eating grass, some of them are looking at the sky and some of them are looking back and sucking their tongue. Were it not for the fact that he often went to the field and made careful investigation, he could not describe such cows so vividly. Whole frame of Five Cows Figure is not very large, $140 \mathrm{~cm}$ long and $21 \mathrm{~cm}$ wide; though it is not very large, it reflects Han Huang's exquisite skills, which is still luminous after thousands of years. In addition, five cows show themselves in full or side face alternatively in the figure, with great changes in front view, which is a whole composition way which may not be achieved by an ordinary painter.

Basic modeling technique of painting of ancient China is dominated by lines, and Five Cows Figure is just a vivid portrayal of Han Huang's skill in line drawing. His lines could draw the articles vividly, different in approach but equally satisfactory in result compared with the skills of Lu Tanwei who was famous for "one-stroke figure". Essence of painting lies in imagery, rather than shape, and the imagery lies in vividness, which may not only need painting talent, but also need genuine learning from a master. By comparison, later generations find that $\mathrm{Lu}$ Tanwei was just one of the teachers of Han Huang. Lu Tanwei was a painter in the Southern Dynasties and inherited technical skills of Gu Kaizhi in the Eastern Jin Dynasty (317-420), that is, one- 
stroke drawing, interline connection and artistic concept. Han Huang also shows similar technical skills in his Five Cows Figure. His strokes were meticulous, exquisite, sophisticated, bold and simple, especially lines of backs of such cows are mild, winding and at one stretch, vigorous and forceful at sparsely-lined area and freely flowing at closelylined area. In addition, their shoulder, neck, head and other body parts are all well coherent and show the perspective relation among all details accurately and vividly. [4]76-77 Han Huang drew Five Cows Figure sophisticatedly, orderly, progressively and easily and his deep insight and extraordinary painting skills are really overwhelming.

Line drawing in painting in ancient China is consistent with calligraphy techniques to a large extent. Han Huang's painting skills not only benefit from his practice in painting, but also are the result of his conscious integration of calligraphy skills and painting. Han Huang's had a solid foundation of calligraphy and he once invited master calligrapher Zhang $\mathrm{Xu}$ as his tutor in his childhood, so he really mastered the essence of the excessively free cursive style of Zhang Xu. So Han Huang often drew his lines freely in his later painting and his hollow strokes always showed infinite power. Like the old saying, "calligraphy and painting are homologous and their stroke principles are the same." Five Cows Figure painted by Han Huang eventually became so unique and even comparable with Painting Sage Wu Daozi by inheriting the free style of Zhang $\mathrm{Xu}$ and drawing from the painting skills of predecessors. Zhang Yanyuan once said, "Wu Daozi's sparse-style painting is exceptional, vivid, consistent and strong." Though the subject of Five Cows Figure is not the pavilions and building or people that Wu Daozi was good at describing, his strokes are as imaginative and rational as that of $\mathrm{Wu}$ Daozi. So the smallsized Five Cows Figure best represents broad and profound aesthetics and great theory of the most flourishing cultural period Tang Dynasty in painting field and show the public a leisurely, comfortable and vigorous artistic conception, achieving the artistic pursuit of harmony between man and nature and gift of nature.

In addition to vivid modeling and skillful techniques, Five Cows Figure is also an outstanding work in ancient Chinese painting in terms of shading and coloring techniques. With the increasingly deepening of national cultural exchange, painting of Tang Dynasty, under the influence of western painting, shows strong feature of combination of Chinese and western ideas in terms of shading technique, which is also reflected in shading and coloring of Five Cows Figure. He made luster and color ink flexible and the figure fully stereoscopic and layered by highlighting changes in the relation between cold and warm colors, and his technique in color application was dramatic in Tang Dynasty.

\section{Dramatic Strokes, with CREation of NeW Style}

Based on horizontal investigation on painting history of Tang Dynasty, it is found that Han Huang's works of rural life highlighted rural customs and people, whiling highlighting cows and sheep. Han Huang also had high attainments in figure painting and his unique style had made him form his own school in figure painting in ancient China.
Of course, different from separate human portrait display in western figure painting, figures in Han Huang's works usually showed themselves under the great rural background. Because Han Huang preferred genre painting with complex contents and layers compared with relatively simple figure painting. Han Huang paid more attention to description of people, farmyards, production, life and rural scenery in rural customs, etc.

It is interesting that Han Huang was listed in Xuanhe Painting Florilegium as a painter of figure painting and called "stroke master". From the above, Han Huang is more like a painter of "livestock" focusing on cows and sheep. Such a definition in Xuanhe Painting Florilegium shows that cow painting is not the whole works of Han Huang or the most unique one to some extent. A saying in the painting history in ancient China "Han Huang's horse painting and Dai Song's cow painting" also shows that Han Huang was not the best cow painter in ancient China. In order to illustrate the point, nearly half of the nearly 40 pieces of Han Huang's works collected in Xuanhe Painting Florilegium were of rural life and the other half were mostly of figures, and only four pieces were of cows. Xuanhe Painting Florilegium also quoted the saying "Han Huang's horse painting and Dai Song's cow painting". "Dai Song" in "Dai Song's cow painting" refers to Painter Dai Song, who was a student of Han Huang. Dai Song's techniques in painting cows were fully inherited from Han Huang. Xuanhe Painting Florilegium defined Han Huang as a figure painter and, instead, defined his student Dai Song as the best cow painter, it may be not because Dai Song did better his teacher or Han Huang made rare relevant works, it needs further study in the field of Chinese painting history. [5]85-86 Anyway, no one could touch Han Huang's achievements in painting field in Tang Dynasty. Han Huang's painting works of rural life created a new field for ancient Chinese painting and was one of the important symbols of flourishing culture in Tang Dynasty.

\section{REFERENCES}

[1] Zhang Yanyuan. Great Painting Views of Past Dynasties [M] Shanghai: Shanghai People's Fine Arts Publishing House, 1964:54-56.

[2] Chen Chuanxi. Complete Works of Chinese Calligraphers [M]. Shijiazhuang: Hebei Education Press, 2004:138-140.

[3] Wang Bomin. History of Chinese Painting [M]. Shanghai: Shanghai People's Fine Arts Publishing House, 1983:163-164.

[4] Yu Jianhua. Classified Collection of Chinese Ancient Painting Theories [M]. Beijing: People's Fine Arts Publishing House, 2000:76-77.

[5] He Zhiming. Comments on Paintings of Tang and Five Dynasties [M]. Changsha: Hunan Fine Arts Publishing House, 1997:85-86. 